\title{
Tissue-Specific and Ubiquitous Factors Binding next to the Glucocorticoid Receptor Modulate Transcription from the Mouse Mammary Tumor Virus Promoter
}

\author{
CHRISTOPHE CAVIN $\dagger$ AND ELENA BUETTI* \\ Swiss Institute for Experimental Cancer Research, CH-1066 Epalinges, Switzerland
}

Received 22 August 1994/Accepted 6 March 1995

\begin{abstract}
Steroid hormones complexed with their receptors play an essential role in the regulation of mouse mammary tumor virus (MMTV) transcription. However, the need for additional tissue-specific regulatory factors is suggested by the lack of virus expression in liver, in which glucocorticoid receptors are highly abundant, and by the tissue-specific transcription of reporter genes linked to an MMTV long terminal repeat in transgenic mice. In this study, we characterized two distal-region regulatory elements, DRa and DRc, which, together with the distal glucocorticoid receptor binding site (DRb), increased transcription from the MMTV promoter in permissive cells. This was demonstrated by transfection of these sequences (DRa, DRb, and DRc) in different combinations with the natural MMTV promoter in mouse fibroblasts and mammary epithelial cells, followed by quantitative S1 nuclease mapping of the transcripts. We further showed by DNase I footprinting, methylation interference, and gel retardation assays with various nuclear extracts from permissive or nonpermissive tissues and cell lines that the factors binding to the DRa site are distinct and tissue-specific whereas those binding to DRc are ubiquitous.
\end{abstract}

Mouse mammary tumor virus (MMTV) is a slow-transforming retrovirus that induces carcinomas of the mammary gland in susceptible mouse strains. The virus can be transmitted either exogenously as viral particles through the milk or endogenously through the germ line as integrated proviruses (reviewed in reference 26). Studies involving the generation of transgenic mice carrying DNA constructs in which the MMTV long terminal repeat (LTR) is linked to a reporter gene $(65,72$, 77 ) or drives the expression of a transforming gene $(44,54)$ showed that the mammary gland is a major site of expression. However, other tissues such as lymphoid organs, salivary glands, seminal vesicles, prostate, and testes were often found to express the transgene at lower levels.

The infection of mammary epithelial cells leads to the insertion of DNA in the host cell genome. Provirus expression involves protein factors binding to specific DNA sequences in the LTR. Steroid hormones such as glucocorticoids (8), progestins $(12,22)$, and androgens $(16,28)$ bound to their receptors were shown to positively regulate MMTV gene expression in cells derived from mammary tumors, in infected cell lines $(62,83)$, and in cells transfected with cloned MMTV DNA $(8$, 13, 32, 39). This class of positively acting factors induces the expression of MMTV through DNA sequences within the U3 region of the LTR. The hormone-responsive element (HRE) extends to approximately $200 \mathrm{bp}$ upstream of the transcription start site $(9,33,43)$. A distal element (around position -175) and a proximal one (around -120), shown to bind the purified glucocorticoid receptor in vitro $(59,69)$, act cooperatively and with other sites of the HRE to achieve maximum glucocorticoid stimulation of the MMTV promoter (Fig. 1) (3, 6, 10, 11, $13,37,48)$. It has been shown that mutations of a binding site for nuclear factor I (around position -70) impair the glucocor-

\footnotetext{
* Corresponding author. Present address: Institute for Microbiology, University of Lausanne, Bugnon 44, CH-1011 Lausanne, Switzerland. Phone: 41 21-314 23 29, 31444100.

$\dagger$ Present address: Centre de Recherche Nestlé, CH-1000 Lausanne 26, Switzerland.
}

ticoid-stimulated transcription from the MMTV promoter, providing evidence for the involvement of a nonreceptor protein in the hormonal response $(10,11,13,48,76)$.

In several studies with transgenic mice carrying the MMTV LTR linked to a reporter gene, the pattern of organs expressing the transgene did not correlate with the abundance of glucocorticoid receptor in their cells. The expression of the transgene was never detected in the liver $(63,65,72)$, despite its high level of glucocorticoid receptor $(25,53)$. Thus, the presence of this receptor does not seem to be sufficient to allow transcription from the MMTV LTR. The tissue tropism of MMTV may be mediated by the combined action of hormone receptors and of modulatory factors bound to cis-acting elements. By functional assays in tissue culture cells, several positive and negative regulatory elements have been identified in the $5^{\prime}$ part of the LTR $(21,29,41,49,50,52,81)$. Moreover, the involvement of regions located outside of the HRE in the tissue-specific expression of MMTV was defined by the generation of transgenic mice (reviewed in reference 26) and by the analysis of cloned MMTV variant proviruses, isolated from T-cell lymphomas, with alterations in the U3 region of their LTRs $(40,47)$. These variants of MMTV display internal deletions of about 400 to $500 \mathrm{bp}$ which are thought to be related to the tissue-specific expression of MMTV in T lymphocytes $(31,74,80)$. The overexpression of MMTV genes in $\mathrm{T}$ lymphocytes and the extended range of expressing organs (also including brain, heart, and skeletal muscle) observed with a reporter transgene under the control of a partially deleted MMTV LTR (65) could be explained by the deletion of negative regulatory elements or by the loss of some tissue-specific elements involved in mammary gland expression.

A possible way of achieving glucocorticoid-dependent transcription may be by interactions between the receptor and additional regulatory factors, as suggested by the results of a previous study from our laboratory (46) that investigated the binding of nuclear proteins to MMTV DNA in the vicinity of the distal glucocorticoid receptor-binding site, the main DNA element required for the glucocorticoid stimulation of MMTV 

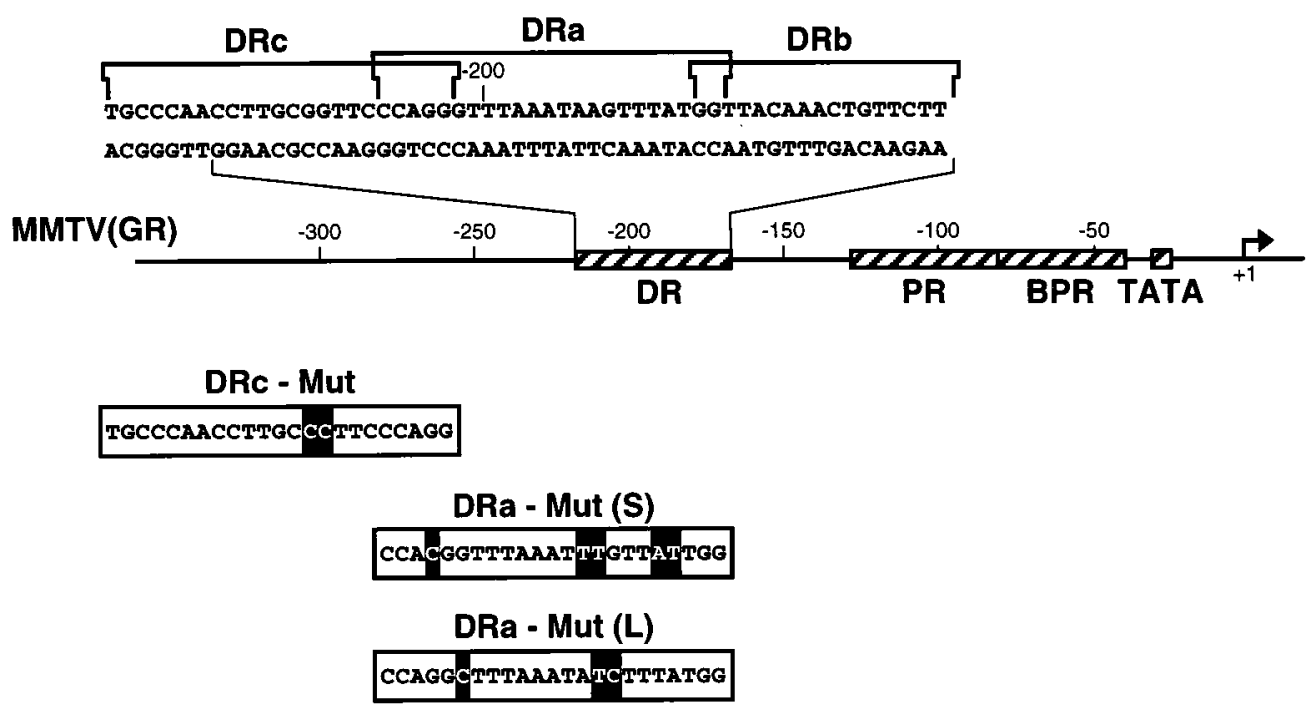

FIG. 1. Schematic representation of the $3^{\prime}$ end of the regulatory region of the MMTV LTR. The TATA box, the basal promoter region (BPR), the proximal region (PR), and the DR are indicated by hatched boxes. DNase I protection assays have defined the distal binding sites for the glucocorticoid receptor (DRb) and for factors binding its $5^{\prime}$ flanking region (DRa). The newly observed protein-binding site (DRc), extending the distal region to position -218 , is located next to DRa. The double-stranded oligonucleotides used in this study are indicated by the brackets above the sequences of DRa, DRb, and DRc in the coding strand. The sequences of the mutated oligonucleotides (coding strand) DRaMut (L), DRaMut (S), and DRcM are shown in the boxes below; white residues in black squares denote the mutated bases.

transcription. By DNase I in vitro footprinting assays using nuclear extracts from mouse liver or salivary glands, an extended protected area was identified in the promoter distal region (DR) around position -200 upstream of the transcription start site (Fig. 1). It was demonstrated that its $3^{\prime}$ part $(\mathrm{DRb},-170$ to -186$)$ interacts with the glucocorticoid receptor, whereas the protected sequence extending to the $5^{\prime}$ side (DRa, -189 to -206 ) showed different hypersensitive sites. Moreover, nuclear extracts from two different tissues (liver and salivary glands) contained proteins that bound to the DRa sequence with a distinct mobility in a gel retardation assay (46).

As liver and salivary glands also differ in their permissivity for MMTV expression in transgenic animals, we decided to pursue and extend the investigation. Using nuclear extracts from various tissues, we confirmed in this study the correlation between permissivity and formation of specific complexes with DRa. We further demonstrated the tissue specificity of the DRa-binding factors by methylation interference and competition with mutated oligonucleotides. In DNase I footprinting experiments, we identified an additional binding activity to a sequence (DRc, -209 to -218 ), located 5' of the DRa region. This activity was found ubiquitously, but its abundance varied in different tissues. We also describe transient transfection experiments designed to determine the functional role of these sequences in the regulation of MMTV transcription in response to glucocorticoid hormones.

\section{MATERIALS AND METHODS}

Cell extracts. (i) For footprinting experiments. Nuclear extracts from livers (10 $\mathrm{g}$ ), kidneys (4 g), and spleens ( $3 \mathrm{~g}$ ) of 103 -month-old BALB/c mice were prepared by the method of Gorski et al. (20), with one modification. Minced tissues were homogenized, cells were broken in the appropriate buffer, and nuclei were pelleted only once through a sucrose cushion and then lysed. Nuclear proteins were resuspended at a final concentration of 5 to $10 \mathrm{mg} / \mathrm{ml}$.

(ii) For gel mobility shift assays. Nuclei from livers $(10 \mathrm{~g})$, kidneys $(4 \mathrm{~g})$, spleens $(3 \mathrm{~g})$, and salivary glands $(2 \mathrm{~g})$ from $10 \mathrm{BALB} / \mathrm{c}$ mice were prepared as previously described by Hagenbüchle and Wellauer (27), with some modifications. Minced tissues were homogenized in $0.3 \mathrm{M}$ sucrose in buffer A $(0.5$ mM EGTA, $2 \mathrm{mM}$ EDTA, $60 \mathrm{mM} \mathrm{KCl}, 15 \mathrm{mM} \mathrm{NaCl}, 0.15 \mathrm{mM}$ spermine, $0.5 \mathrm{mM}$ spermidine, $15 \mathrm{mM} N$-2-hydroxyethylpiperazine- $N^{\prime}$-ethanesulfonic acid
[HEPES; pH 7.5], $14 \mathrm{mM}$ 2-mercaptoethanol). The homogenate was filtered and layered on top of a $10-\mathrm{ml}$ cushion of $30 \%$ (wt/vol) sucrose in buffer A prior to centrifugation for $10 \mathrm{~min}$ at $1,000 \times g\left(\mathrm{HB}-4\right.$ swing-out rotor) and $4^{\circ} \mathrm{C}$. The nuclear pellet was resuspended in $3 \mathrm{ml}$ of $2 \mathrm{M}$ sucrose in buffer A containing only $0.1 \mathrm{mM}$ EGTA and $0.1 \mathrm{mM}$ EDTA, layered on top of a 2-ml cushion of the same solution, and recentrifuged in a Beckman SW50.1 rotor at $100,000 \times g$ for $1 \mathrm{~h}$ at $4^{\circ} \mathrm{C}$. The nuclei contained in the pellet were resuspended in buffer $\mathrm{B}(20 \mathrm{mM}$ Tris- $\mathrm{HCl}$ [pH 7.9], $75 \mathrm{mM} \mathrm{NaCl}, 0.5 \mathrm{mM}$ EDTA, $0.85 \mathrm{mM}$ dithiothreitol, $0.5 \mathrm{mM}$ phenylmethylsulfonyl fluoride, $25 \%$ [vol/vol] glycerol), counted, recentrifuged, and resuspended in this buffer at a concentration of approximately $10^{5}$ nuclei per $\mu l$. Nuclear extracts from mouse mammary glands were prepared as described by De Groot and Sassone-Corsi (17)

Whole-cell extracts from mouse cell lines (fibroblast $\mathrm{L}$ cells $\left[\mathrm{Ltk}^{-}\right]$, normal mammary epithelial cells [EF43], mammary tumor cells [GR], B-cell hybridoma [LBB], and T-cell lymphoma [RG17]) were prepared by the method of Paterson and Everett (57). All extracts were made in the presence of the protease inhibitor phenylmethylsulfonyl fluoride $(0.5 \mathrm{mM})$.

DNase I footprinting. DNase I footprinting assays were performed according to published modifications (46) of the original method (18). An asymmetrically radiolabeled DNA probe was prepared by incubation of plasmid pGLTR (provided by B. Kühnel) with HindIII (cleaving at position +48 , where a synthetic HindIII linker was inserted) followed by $5^{\prime}$ end labeling with $\left[\gamma^{32} \mathrm{P}\right] \mathrm{ATP}$ and digestion with StyI (position -303). The purified labeled fragment (5 fmol) was incubated on ice for $30 \mathrm{~min}$ with $1 \mu \mathrm{g}$ of double-stranded poly(dI-dC) competitor DNA and $60 \mu \mathrm{g}$ of liver, kidney, or spleen nuclear extracts in a $20-\mu l$ binding reaction mixture as previously described (46). In competition experiments, the indicated amount of double-stranded oligonucleotides in $1 \mu \mathrm{l}$ was added to the binding reaction mixture $10 \mathrm{~min}$ prior to the addition of the labeled DNA.

DNase I (Pharmacia) at 5,000 $\mathrm{U} / \mathrm{ml}$ was freshly diluted as necessary (to approximately $250 \mathrm{U} / \mathrm{ml}$ ), and $1 \mu \mathrm{l}$ was added to the binding reaction mixture. Digestion was allowed to proceed for 3 to $5 \mathrm{~min}$ on ice and was stopped by adding $180 \mu \mathrm{l}$ of a solution containing sodium dodecyl sulfate and proteinase K (46). Reextracted DNA samples were loaded onto a $6 \%$ denaturing polyacrylamide gel.

Gel mobility shift assays. Oligonucleotides DRa, DRaMut(L) (DRaML), DRaMut(S) (DRaMS), DRc, and DRcM (Fig. 1) were labeled at the 5' end with $\left[\gamma^{-32} \mathrm{P}\right]$ ATP and T4 polynucleotide kinase before annealing with the complementary strand. A portion $(20 \mathrm{fmol})$ was incubated on ice for $30 \mathrm{~min}$ in a $20-\mu \mathrm{l}$ binding reaction mixture containing $4 \mu \mathrm{l}$ of buffer $(175 \mathrm{mM} \mathrm{NaCl}, 55 \mathrm{mM}$ HEPES [pH 7.6], $40 \mathrm{mM} \mathrm{MgCl}_{2}, 0.5 \mathrm{mM}$ EDTA, $55 \%$ glycerol), $1 \mathrm{mM}$ dithiothreitol, $1 \mu \mathrm{g}$ of double-stranded poly(dI-dC) competitor DNA, and $20 \mu \mathrm{g}$ of whole-cell nuclear protein from cultured cell lines. In the case of extracts from mouse tissues, $5 \times 10^{5}$ nuclei of spleen or $10^{6}$ nuclei of liver or kidney were used with the DRa, DRaML, and DRaMS oligonucleotides, and conversely for the DRc and DRcM oligonucleotides. With the mammary gland nuclear extract, 5 to $10 \mu \mathrm{g}$ was used in the different reactions. The salt concentration in the protein- 
DNA binding reaction mixture was adjusted to $60 \mathrm{mM}$ as in the whole-cell extract. Samples were analyzed on a $5 \%$ nondenaturing polyacrylamide gel.

Methylation interference experiments. Double-stranded oligonucleotides DRa and DRc, ${ }^{32} \mathrm{P}$-labeled at the $5^{\prime}$ end of the coding strand as for gel mobility shift assays, were methylated in $200 \mu \mathrm{l}$ of $50 \mathrm{mM}$ sodium cacodylate- $1 \mathrm{mM}$ EDTA (pH 8.0) by addition of 1 to $4 \mu$ l of $98.9 \%$ dimethyl sulfate and incubation for $5 \mathrm{~min}$ at room temperature. The reaction was stopped by adding $40 \mu \mathrm{l}$ of 1.5 $\mathrm{M}$ sodium acetate ( $\mathrm{pH}$ 7.0)-1.0 M 2-mercaptoethanol. After two precipitations with ethanol, the DNA was incubated with nuclei from mouse tissues (liver and spleen) to perform a gel mobility shift assay. Double-stranded oligonucleotides bound to proteins as well as unbound ones were electroeluted from the respective gel slices and ethanol precipitated. $\mathrm{G}>>\mathrm{A}>>\mathrm{T}$ or $\mathrm{G}$ cleavages of the eluted methylated duplexes were performed with $\mathrm{NaOH}$ or piperidine. These procedures as well as electrophoresis in $20 \%$ acrylamide- $7 \mathrm{M}$ urea gels were carried out according to published protocols (45).

Plasmid constructions. Construction of plasmids pLS wild type and pLS -172/ -162 was described previously $(10,37)$. They consist of the MMTV (GR strain) LTR (either wild type or with an 8-bp HindIII linker replacing the DNA between positions -172 and -162 ) in front of the coding portion of the herpesvirus thymidine kinase gene in a pBR322 vector. Plasmids pLS DRb, pLS DRb $+\mathrm{a}$, and pLS DRb $+a+c$ were newly constructed and used for the generation of pLS $\mathrm{DRb}+\mathrm{c}$ and $\mathrm{pLS} \mathrm{DRb}+\mathrm{a}+\mathrm{c}+\mathrm{c}$. Plasmid $\mathrm{pLS}-172 /-162$ was digested with HindIII and EcoRI. The DNA fragment containing the 5' end of the LTR was removed and replaced by double-stranded oligonucleotides with the sequence of $\mathrm{DRb}$ alone, $\mathrm{DRb}+\mathrm{a}$, or $\mathrm{DRb}+\mathrm{a}+\mathrm{c}$ and a HindIII cohesive end (Fig. 1). Plasmids $p L S D R b+c$ and $p L S D R b+a+c+c$ were obtained by blunt-end ligation of the double-stranded DRc oligonucleotide in front of either the DRb (in pLS DRb) or the DRc (in pLS DRb $+\mathrm{a}+\mathrm{c}$ ) sequence. The presence and orientation of the different inserts were verified by sequencing.

Cell culture and transfection. Mouse Ltk ${ }^{-}$cells were cultured in Dulbecco's modified Eagle's medium supplemented with $10 \%$ fetal calf serum and antibiotics. Mouse mammary epithelial EF43 cells were grown in this medium with addition of insulin $(5 \mu \mathrm{g} / \mathrm{ml})$ and epidermal growth factor $(10 \mathrm{ng} / \mathrm{ml})$. Cells were grown in 100-mm-diameter culture dishes until they reached approximately 60 to $70 \%$ confluency. Transient transfections were carried out by the DEAE-dextran method with $15 \mu \mathrm{g}$ of MMTV plasmid and $1 \mu \mathrm{g}$ of plasmid H514, containing the rabbit $\beta$-globin gene and simian virus 40 enhancer sequences (4). The cultures were incubated with DNA for $6 \mathrm{~h}$, subjected to a $10 \%$ dimethyl sulfoxide shock for $1.5 \mathrm{~min}$ at room temperature, washed, and incubated with complete medium for a further $42 \mathrm{~h}$. Dexamethasone (Sigma) was added to a final concentration of $5 \times 10^{-7} \mathrm{M}, 17 \mathrm{~h}$ before RNA extraction.

RNA extraction and S1 mapping. Total cellular RNA was extracted from transiently transfected cells by the guanidinium thiocyanate method, digested with RNase-free DNase I, extracted with phenol-chloroform, and reprecipitated with ethanol. For the S1 nuclease mapping experiments, the following DNA fragments were labeled at the $5^{\prime}$ end with $\left[\gamma_{-}{ }^{32} \mathrm{P}\right]$ ATP: for the analysis of MMTV transcripts, the EcoRI-Bam HI fragment of plasmid p $\Delta 47 \mathrm{~B}$ (37) extending from -204 to +142 ; for the $\beta$-globin internal standard, the $2.5-\mathrm{kb}$ Bam HI fragment of pH514 (37). RNA ( 25 or $50 \mu \mathrm{g}$ ) was hybridized to 5 or $10 \mathrm{fmol}$ of $5^{\prime}$ end-labeled MMTV or $\beta$-globin probe in $20 \mu \mathrm{l}$ at $52^{\circ} \mathrm{C}$ for $16 \mathrm{~h}$ and digested with $1,000 \mathrm{U}$ of $\mathrm{S} 1$ nuclease per $\mathrm{ml}$ for $45 \mathrm{~min}$ at room temperature. Protected fragments were separated by electrophoresis in denaturing $6 \%$ polyacrylamide gels and subjected to autoradiography. The intensity of the bands was quantified by densitometric scanning of the films.

\section{RESULTS}

Tissue-specific and ubiquitous proteins binding to the distal region of the MMTV promoter. For the analysis of proteins binding in the vicinity of the distal glucocorticoid regulatory element (DRb site; from -170 to -186$)$, we prepared nuclear extracts from three different mouse organs: spleen (permissive for MMTV expression) and liver and kidney (both nonpermissive tissues). DNase I footprinting experiments were performed with a radiolabeled DNA fragment spanning the promoter region of MMTV (from -303 to +48 ) and unfractionated nuclear extracts from these tissues. Two predominant areas of the coding strand were protected from DNase I cleavage (Fig. 2A), one in the DR and the other in the basal promoter region.

In the $\mathrm{DR}$, the $3^{\prime}$ part of the footprint (DRb) was very similar with all tissue extracts and is due to the glucocorticoid receptor, as shown previously (46). The protection extending to the $5^{\prime}$ side (DRa, -189 to -206 ) showed tissue-specific differences, indicating the presence of a binding activity that is distinct from the glucocorticoid receptor. With liver (Fig. 2A, lane 2) and kidney (data not shown) nuclear extracts, two strong hypersensitive sites were observed at the 5' boundary of
DRa at positions -207 and -208 , in agreement with results obtained previously in our laboratory, whereas with the spleen extract (Fig. 2A, lane 3), the protected area extended to position -218 without interruptions. The additional protein-binding site, located upstream from $\mathrm{DRa}$, was designated DRc $(-207$ to -218$)$. Interestingly, closer examination of the footprints obtained with salivary glands and L-cell nuclear extracts by Meulia and Diggelmann (46) revealed a similar extended protected area with no hypersensitive sites at the 5 ' boundary of DRa. Thus, the presence of hypersensitive sites between DRa and DRc seems to be a particular feature of nonpermissive tissues. A DRc-binding activity also exists in nonpermissive tissues, as shown by the smaller protected area from -211 to -218 seen with liver nuclear extract (Fig. 2A, lane 2).

To investigate whether one or more binding activities were involved in the protection of DRa and DRc, we performed oligonucleotide competition experiments. In spleen nuclear extract, a 500-fold molar excess of a double-stranded DRc oligonucleotide (Fig. 1) abolished the protection of DRc but not of DRa (Fig. 2B, lane 9), indicating that two distinct binding activities contribute to the extended footprint up to position -218. In liver nuclear extract, competition with the DRc oligonucleotide caused the disappearance of the footprint between -211 and -218 (Fig. 2C, lane 3). With both types of extracts, we observed that competition with the DRc oligonucleotide also impaired the protection of $\mathrm{DRb}$, suggesting that the binding of the glucocorticoid receptor is affected. Control experiments with a 500 -fold molar excess of the nonspecific competitor VW, containing the sequence of the promoter region of adenovirus type 2 (67), did not alter the DNase I protection pattern seen in the absence of competitor (Fig. 2B, lane 8; Fig. 2C, lane 4).

Double-stranded oligonucleotides with either the DRa or the DRb sequence (Fig. 1) competed for the footprint in the homologous region (Fig. 2B), showing that two distinct binding activities of spleen (permissive) nuclear extracts were responsible for the footprint from -170 to -207 (Fig. 2B, lane 6 and 7). A binding activity distinct from the glucocorticoid receptor was also seen with liver (nonpermissive) nuclear extracts (Fig. $2 \mathrm{~B}$, lane 3 and 4) as previously observed (46). At a 500-fold molar excess, the DRb oligonucleotide also affected the footprint in DRc (Fig. 2B, lane 3). Likewise, competition with the DRa oligonucleotide altered the footprint in DRb (Fig. 2B, lane 7).

Tissue-specific features were also observed in the basal promoter region. As expected, extracts from all tested tissues protected an area covering the nuclear factor I and III (Oct-1) recognition sites $(7,46,56)$. However, with the nonpermissive tissue extracts (liver and kidney), the protected area extended to DNA sequences closer to the TATA box, while with the permissive tissue extracts (spleen), the protection extended further upstream, in the direction of the proximal region (Fig. 2). The pattern observed with the spleen extract may be representative of permissive tissues in general, as it was also displayed by nuclear extracts of salivary glands (46).

As the results of the footprinting experiments showed that the major differences between extracts from permissive and nonpermissive tissues concerned the $5^{\prime}$ part (DRa and DRc) of the DR, we performed gel retardation assays using oligonucleotides with the DRa or the DRc sequence (Fig. 3). Extracts from murine permissive cell lines (Ltk ${ }^{-}$fibroblasts, EF43 normal mammary epithelial cells, GR mammary tumor cells, and the lymphoid cell lines RG17 and LBB) and from lactating mammary glands were used, in addition to the tissue extracts mentioned previously for the footprinting experiments. When the labeled DRa oligonucleotide was incubated with the different nuclear extracts, two distinct major DNA-protein com- 


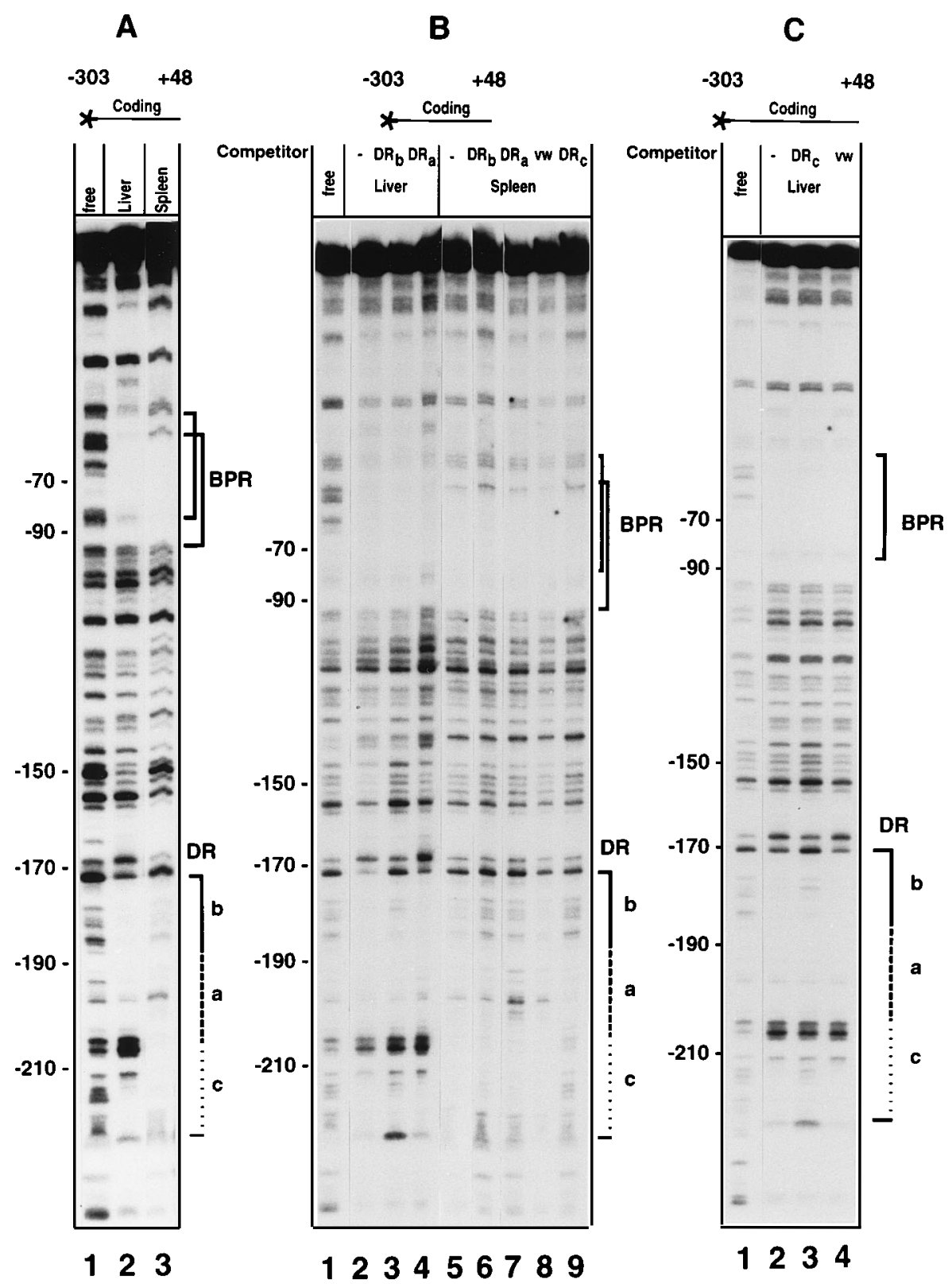

FIG. 2. DNase I footprinting analysis with crude liver and spleen nuclear extracts. A DNA fragment comprising the sequences from the StyI restriction site at positions -303 to +48 , where a synthetic HindIII linker was inserted, was 5' labeled at the StyI site. The 352-bp fragment was incubated with $25 \mu \mathrm{g}$ of bovine serum albumin (lane 1) or with $50 \mu \mathrm{g}$ of nuclear proteins from liver (A, lane 2; B, lanes 2 to 4 ; C, lanes 2 to 4 ) or spleen (A, lane 3; B, lanes 5 to 9 ). The complexes were then subjected to DNase I digestion. The two major protected areas in the basal promoter region (BPR) and in the DR are indicated by brackets. In competition experiments (B and C), oligonucleotide DRb, DRa, or DRc (see Fig. 1) was preincubated with the extracts in 500-fold molar excess over the labeled probe. The nonspecific competitor VW from the adenovirus promoter was also added at 500-fold molar excess (B, lane 8; C, lane 4).

plexes were observed (Fig. 3A, large arrows). All of the extracts from permissive tissues or cells formed complexes with similar mobilities (Fig. 3A, lanes 2 to 8), migrating faster than those formed by the nonpermissive extracts (Fig. 3A, lane 1; see also Fig. 6B, lane 2). We noticed that in gel retardation assays performed in $2 \%$ agarose rather than $5 \%$ polyacrylamide, the mobility of the complexes formed with permissive tissue extracts (e.g., spleen and L cells) was slightly lower than that of complexes formed with nonpermissive extracts, in agreement with previous observations (salivary glands [46]) (data not shown). It is likely that the permissive tissue complexes described in this and the previous study (46) are highly related, especially since the patterns of DNase I protection were identical for spleen, salivary glands, and L cells (showing no hypersensitive sites at positions -207 and -208 in contrast to nonpermissive tissues). The lower band in Fig. 3A, lane 1 (marked by a small arrow) was present in variable amounts in different experiments and is most likely due to proteolytic cleavage (compare Fig. 3A, lane 1, with Fig. 6A, lane 1). In quantitative terms, lower amounts of DRa-bound complexes were observed with permissive extracts than with nonpermissive extracts, suggesting a low level of expression or a weak affinity for the DRa sequence.

In contrast, when the DRc oligonucleotide was incubated 


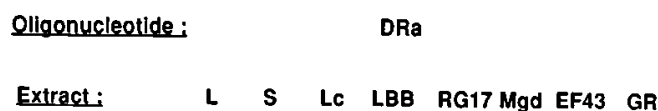

(A)

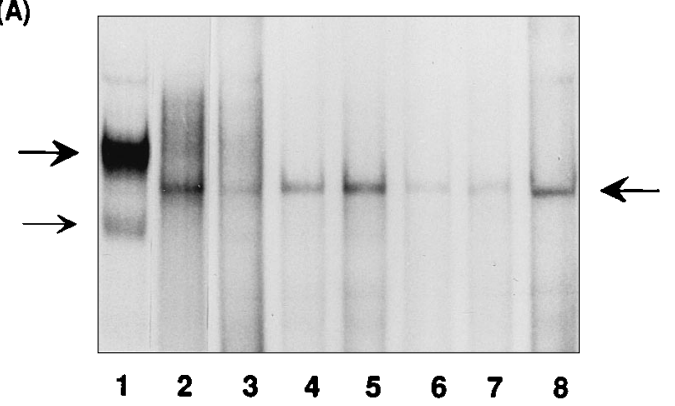

Oligonucleotide: $\quad$ DRc

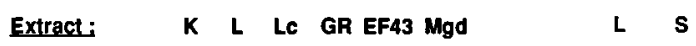

(B)

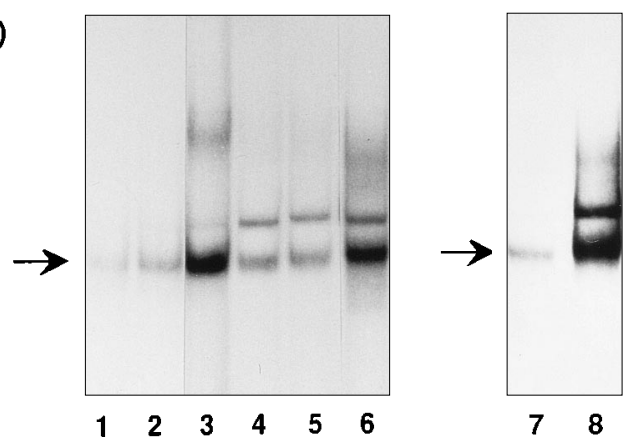

FIG. 3. Gel retardation assays using extracts from different sources and 5 'end-labeled oligonucleotide DRa (A) or DRc (B). (A) Oligonucleotide DRa was incubated with extracts from nonpermissive tissue (liver [L; lane 1]) or from permissive tissues (spleen [S; lane 2] and mammary gland [Mgd; lane 6] or other cell types (fibroblasts [L cells $\{\mathrm{Lc}\}]$, B-cell hybridoma [LBB], T-cell lymphoma [RG17], mammary epithelial cells [EF43], and mammary tumor cells [GR]; lanes 3 to 8 ). The upper arrow on the left indicates the specific DNA-protein complex for nonpermissive tissues, and the arrow on the right indicates the specific complex for permissive tissues or cells. (B) The labeled oligonucleotide DRc was incubated with liver (L; lanes 2 and 7), kidney (K; lane 1), or spleen (S; lane 8) nuclei or with nuclear extracts from the other cell types (lanes 3 to 6 ). The arrows on the left indicate the specific DNA-protein complex.

with nuclear extracts from both permissive (Fig. 3B, lanes 3 to 6 and 8 ) and nonpermissive tissues or cells (lanes 1, 2, and 7), the specific protein-DNA complex exhibited the same gel mobility. However, the intensity of the signal was stronger when extracts from permissive tissues were used. This result indicates a quantitative rather than a qualitative difference between the two types of extracts, suggesting that the abundance of DRc-binding factor(s) is higher in permissive organs. The upper band seen in some experiments is due to nonspecific binding and is not reproducible (see Fig. 7).

Methylation interference analysis of the DNA-protein contact points in DRa and DRc. By gel retardation assay, we observed the formation of complexes with different mobilities (in DRa) or with the same mobility (in DRc). To further characterize the complexes, we decided to perform methylation interference assays, which allow the determination of the protein-DNA contact points, on these DNA sequences (Fig. 4). The double-stranded oligonucleotides DRa and DRc, labeled on one strand and partially methylated, were used as substrates in a reaction with dimethyl sulfate and thereafter as probes in a gel retardation assay. The bound (Fig. 4, lanes B) and free (lanes F) forms of DNA were recovered from the native gel, cleaved with piperidine or $\mathrm{NaOH}$, and analyzed on denaturing polyacrylamide gels. If methylation at a particular residue interferes with protein binding, the corresponding band in the autoradiograph is underrepresented in the population of protein-bound fragments (lanes B).

When the DRa oligonucleotide was incubated with liver nuclear extract (Fig. 4A), we observed the disappearance of certain bands in lane 4 (bound) compared with lane 3 (free), indicating the specific $\mathrm{G}$ bases which interact with protein. This pattern of contact points was different from the pattern obtained with proteins from a permissive nuclear extract (spleen; lane 2), for which no reduction of the signals was observed. To determine contact points on DRa with proteins from spleen nuclear extract, the methylated DNA was cleaved with $\mathrm{NaOH}$ instead of piperidine, thus allowing the analysis of a broader spectrum of bases $(\mathrm{G}>>\mathrm{A}[>>\mathrm{T}$ if high concentrations of dimethyl sulfate are used]; Fig. 4B). Only a partial interference was observed, which could be explained by the low amount of complexes found in the gel retardation assays. The results obtained for liver with $\mathrm{NaOH}$ treatment (Fig. 4C) confirmed and extended those of Fig. 4A. On the other hand, the contact points on DRc with nuclear extracts from liver, spleen, or L cells were all the same (Fig. 4D). In conclusion, proteins from the various extracts which formed similarly migrating complexes with DRc also had identical contact points with the DNA (Fig. 5). Conversely, in DRa, proteins from permissive and nonpermissive tissues showed different sets of contact points with the DNA (Fig. 5), further supporting the evidence from the footprinting and gel retardation assays for two distinct DRa-binding activities.

Specificity of the DNA-protein interactions. To prove that the protein-DNA complexes observed with DRa were tissue specific, gel retardation assays were performed with doublestranded oligonucleotides (Fig. 1) mutated in the specific residues shown by methylation interference to be important for the binding of proteins from the different extracts. Compared with wild-type DRa (Fig. 6A, lane 1; Fig. 6B, lanes 1 and 2), oligonucleotide DRaML, carrying three mutations in the liverspecific contact points, no longer formed the specific complex with extracts from liver (Fig. 6A, lane 2) or from kidney, another nonpermissive tissue (Fig. 6B, lane 3). In contrast, oligonucleotide DRaML was not impaired in the formation of the permissive-tissue complex (Fig. 6A, lane 7); it was rather more efficient than wild-type DRa, possibly by fortuitously creating a better binding site (Fig. 6A; compare lanes 6 and 7). This fact may account for the low level of permissive-type complex seen with the nonpermissive kidney extract and oligonucleotide DRaML (Fig. 6B, lane 3), a complex which is normally barely detectable with the wild-type DRa oligonucleotide (Fig. 3A, lane 1; Fig. 6A, lane 1; Fig. 6B, lane 2) but which does appear occasionally in liver extracts (Fig. 6B, lane 1).

The specificity of the protein-DNA complexes formed with the DRa site was determined by competition with homologous or heterologous oligonucleotides. A 250-fold molar excess of the unlabeled DRa oligonucleotide abolished the binding of proteins from either permissive or nonpermissive extracts to the labeled DRa probe (Fig. 6A, lanes 3 and 8), whereas an unrelated oligonucleotide (VW) did not show any competition (Fig. 6A, lanes 5 and 10). The mutated oligonucleotide DRaML at a 250-fold molar excess did not compete for the major DRa-binding activity from liver or kidney tissues (Fig. 6A, lane 4; Fig. 6B, lane 5), whereas it abolished the binding of proteins from spleen to the DRa sequence (Fig. 6A, lane 9). 


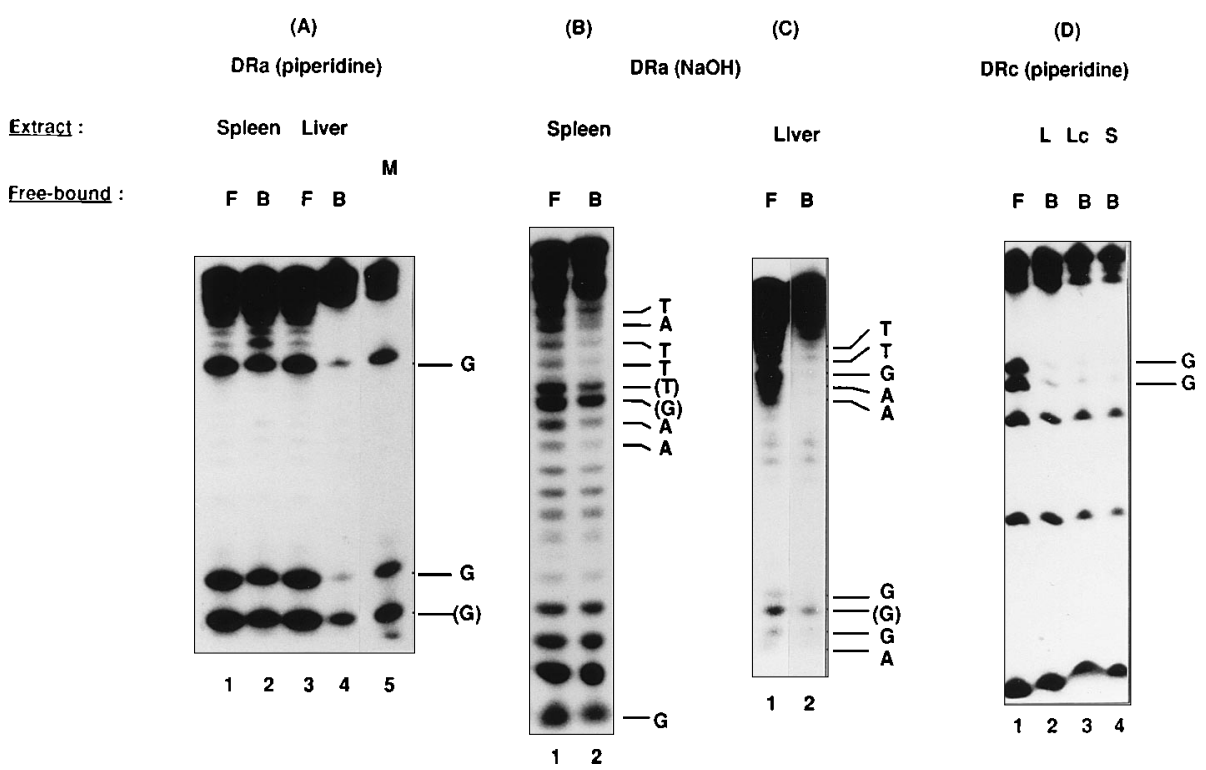

FIG. 4. DNA methylation interference experiments with end-labeled oligonucleotide DRa (A to C) or DRc (D) and nuclei from liver (L), spleen (S), or L cells (Lc). The formed complexes were resolved on a nondenaturing acrylamide gel. Oligonucleotides bound to proteins as well as free ones were isolated from the gel and used for strand cleavage reactions (piperidine, $[\mathrm{A}$ and $\mathrm{D}]$ or $\mathrm{NaOH}[\mathrm{B}$ and $\mathrm{C}]$ ), followed by electrophoresis on a $15 \%$ polyacrylamide sequencing gel. The protein-bound fragments (B) and the free fragments (F) were compared. Relevant residues are indicated. The results of the $\mathrm{NaOH}$ treatment were used to analyze the last $\mathrm{G}$ nucleotide at the $3^{\prime}$ extremity of the DRa sequence (B and C), as the fragments cleaved at this nucleotide after piperidine treatment were not visible on the gel (A).

These results demonstrate that the major DRa-binding species are different in permissive and nonpermissive tissues.

To determine if the proteins from permissive tissues of different origin had a common specificity to the DRa sequence, we used an oligonucleotide (DRaMS; Fig. 1) mutated in five contacted bases that are important for binding with spleen and LBB nuclear extracts. Compared with the DRa probe (Fig. 6C, odd-numbered lanes), the DRaMS sequence (Fig. 6C, evennumbered lanes) bound only very weakly to protein extracts from spleen and all other permissive tissues or cell lines tested, suggesting that the DRa-binding activities in these tissues are the same.

Similar experiments were carried out with an oligonucleotide mutated in two contacted bases of DRc (DRcM; Fig. 1). DRcM was unable to form specific complexes with either type of nuclear protein extracts tested (Fig. 7, lanes 2 and 7), nor did it compete for complex formation with the wild-type DRc sequence (lanes 4 and 9). While Fig. 7 shows the data for two
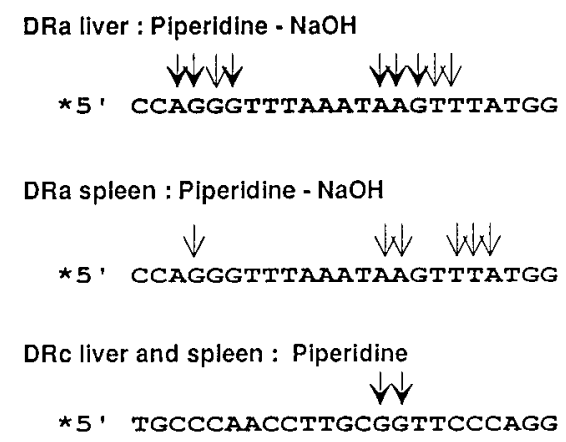

FIG. 5. Summary of DNA methylation interference analysis on the coding strand for the DRa and DRc sequences. Data are from several experiments. Residues which interfere with protein binding are marked; a high degree of interference is represented by a thick arrow, and a partial interference is indicated by a thin arrow. prototype tissues (liver and spleen), several organs and cell types were also studied (kidney, salivary glands, mammary glands, and cell lines $\mathrm{Ltk}^{-}$, GR, EF43, LBB, and RG17; data not shown); they all formed similar retarded complexes with the DRc oligonucleotide (Fig. 2B) and were unable to bind DRcM. Thus, contrary to DRa, no tissue specificity was observed with the DRc sequence, demonstrating the ubiquity of the factors involved.

Influence of the DRa and DRc sequences on MMTV promoter activity. The tissue specificity of the factor(s) binding DRa established the basis for an investigation of the functional role of this region in a permissive situation. We used transient transfection experiments in fibroblastic $\left(\mathrm{Ltk}^{-}\right)$and mammary epithelial (EF43) cells to determine if the presence of the sequences DRa and/or DRc could modify the level of transcription from the MMTV promoter and influence the hormone response. At first, three types of plasmids with the MMTV promoter linked to the coding region of the herpes simplex virus thymidine kinase gene were used. They contained the $3^{\prime}$ part of the MMTV LTR from positions +134 to -162 , to which synthetic double-stranded oligonucleotide DRb, $\mathrm{DR} a+b$, or DRc $+\mathrm{a}+\mathrm{b}$ was added via a HindIII linker which was shown previously not to interfere with the hormone response (10). A plasmid with the complete LTR (pLS wild type) served as a control in these experiments. The different constructions were transiently introduced into $\mathrm{Ltk}^{-}$cells, known to transcribe the MMTV promoter very efficiently after treatment with dexamethasone (a synthetic glucocorticoid), or into EF43 cells in cotransfection experiments with a reference plasmid containing the rabbit $\beta$-globin gene under the control of the simian virus 40 enhancer (4). Correctly initiated mRNA was detected in nuclease S1 protection experiments with $5^{\prime}$ end-labeled DNA probes. Fragments of 142 nucleotides (nt) for MMTV and $212 \mathrm{nt}$ for globin were protected from S1 digestion, and the intensity of these bands was measured by densitometry of the autoradiographs (see Fig. 9). 

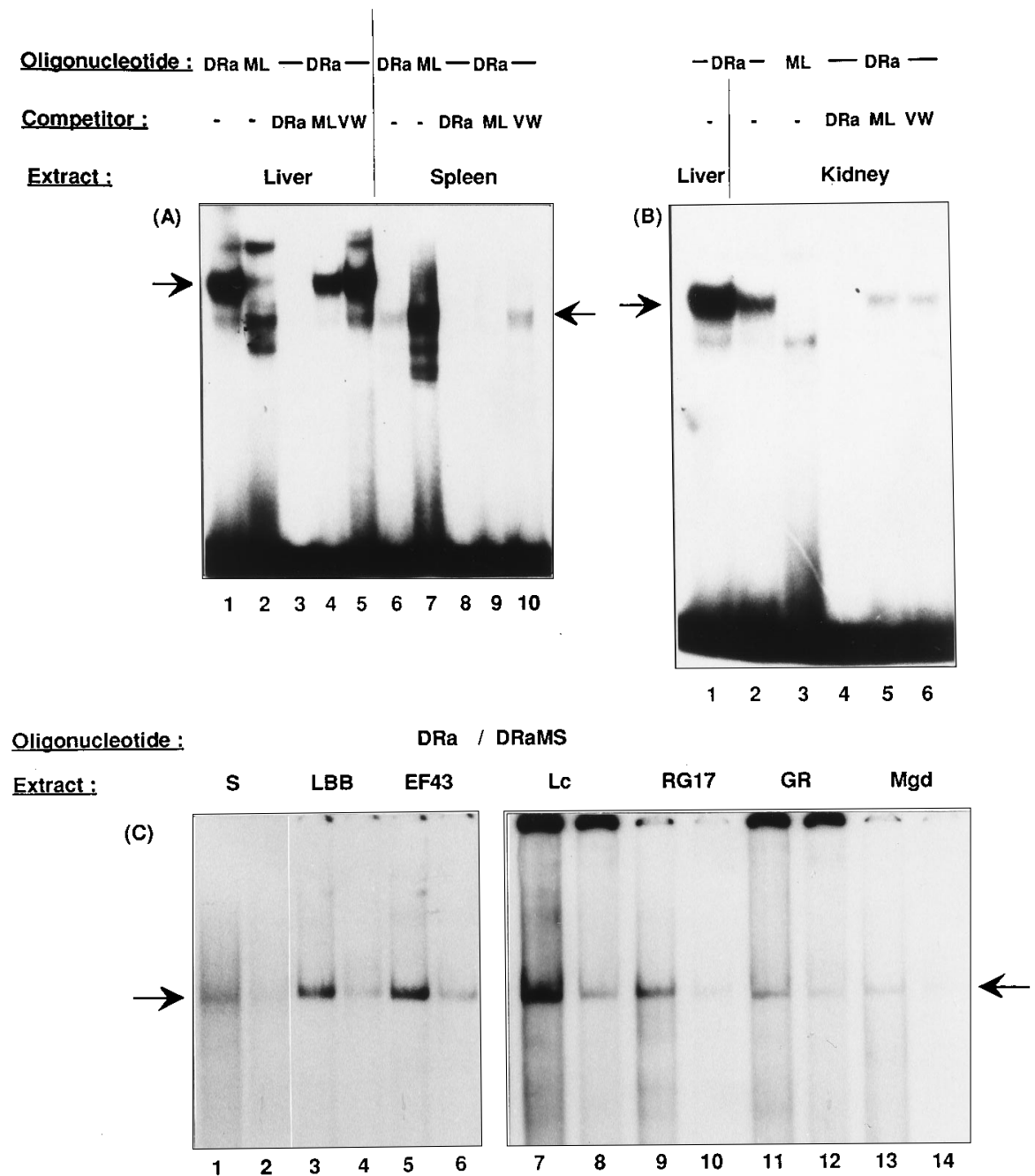

FIG. 6. Gel retardation assays using nuclear extracts from different tissues and end-labeled oligonucleotides from DRa (top line). (A and B) Oligonucleotide DRaML (lanes ML) was mutated in three bases (see Fig. 1) shown to be important for binding proteins from nonpermissive tissues (liver and kidney). The formed complexes were resolved on a nondenaturing polyacrylamide gel. Where indicated, a 250-fold molar excess of competitor DNA (homologous, heterologous, or nonspecific [VW] oligonucleotide) was included in the preincubation mixture. (C) End-labeled probes were oligonucleotides DRa (odd-numbered lanes) and DRaMS (even-numbered lanes). DRaMS was mutated on five bases (see Fig. 1) shown to be important for binding factors from permissive tissues. Nuclear extracts used were from spleen (S), mammary gland (Mgd), B-cell hybridoma (LBB), normal mammary epithelial cells (EF43), fibroblasts (L cell [Lc]), a T-cell lymphoma (RG17), and mammary tumor cells (GR). The arrows on each side indicate the specific DNA-protein complex.

The results of several experiments with $\mathrm{Ltk}^{-}$and EF43 cells consistently showed that plasmid pLS DRb, which did not contain any additional MMTV sequences upstream of the distal glucocorticoid receptor-binding site, had the lowest level of expression in both cell lines (Fig. 8A and B; Fig. 9A). The $\mathrm{DRa}+\mathrm{b}$ construct, which contained the tissue-specific factorbinding site (DRa) adjacent to the distal glucocorticoid receptor-binding site (DRb), produced only a slight (1.6-fold) increase in transcription compared with DRb alone. The further addition of the DRc sequence $5^{\prime}$ to the DRa element, in $\mathrm{DRc}+\mathrm{a}+\mathrm{b}$, produced a 3.7- to 5.1-fold increase in the dexamethasone-induced mRNA level in $\mathrm{Ltk}^{-}$cells and in EF43 cells. In comparison, addition of the remaining 1,000 nucleotides up to the $5^{\prime}$ end of the LTR (pLS wild type) showed a further increase in transcription of only 2-fold (7.2- to 11.4-fold compared with DRb alone), as a result of the combined effect of positive and negative regulatory factors which bind in this region (reviewed in reference 26). Thus, the presence of only $40 \mathrm{bp}$ upstream of the glucocorticoid receptor-binding site is able to positively modulate the level of transcription from the MMTV promoter in permissive cell lines.

To better define the roles of the DRa and DRc sites, we prepared two new plasmids, DRc $+b$ and $D R c+c+a+b$, for use in transient transfection assays of $\mathrm{Ltk}^{-}$cells. With plasmid $\mathrm{DRc}+\mathrm{b}$, we wanted to determine if the presence of the DRc sequence directly adjacent to the glucocorticoid receptor-binding site $(\mathrm{DRb})$, without $\mathrm{DRa}$, was sufficient to positively influence the expression level. We also tested if the addition of a second DRc sequence in tandem with the first one, in the construct DRc $+c+a+b$, could further increase the level of transcription compared with that found with $\mathrm{DRc}+\mathrm{a}+\mathrm{b}$, as many positive regulatory regions were shown to increase their potency when present in several copies (68). The results showed that the DRc+b plasmid, lacking the tissue-specific factor-binding site (DRa), expressed the thymidine kinase gene at a level which was only slightly higher (1.4-fold) than that of the reference plasmid with DRb alone (Fig. 8C and 9B). The construct $\mathrm{DRc}+\mathrm{c}+\mathrm{a}+\mathrm{b}$, containing two DRc sequences, 


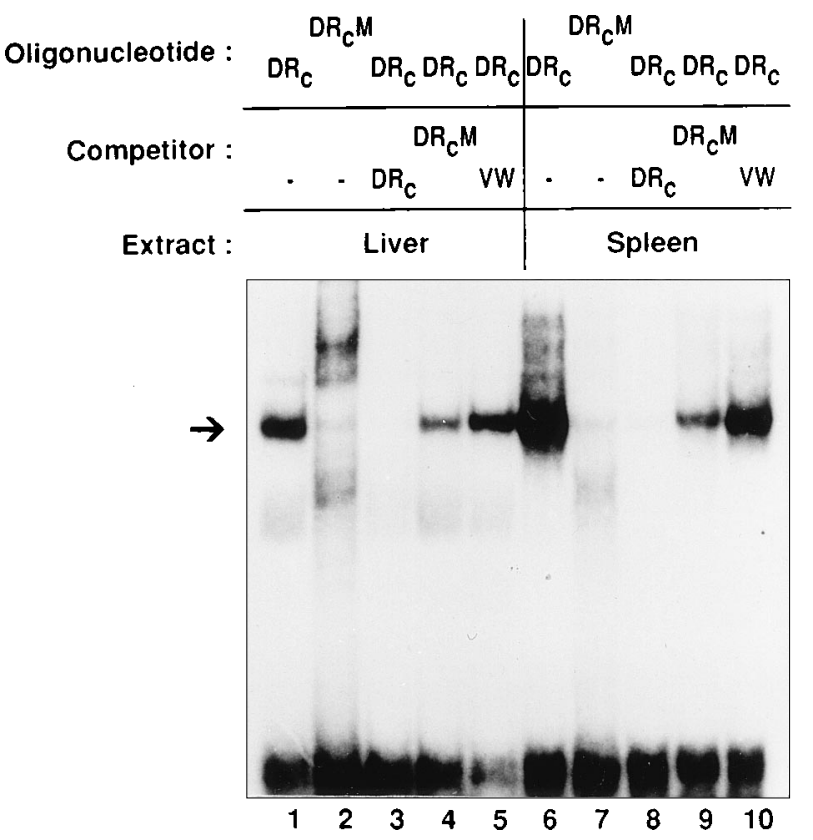

FIG. 7. Gel retardation assay using liver and spleen extracts and end-labeled DRc or mutated DRcM oligonucleotide. DRcM (see Fig. 1) contains mutations in two contacted bases shown to be important for binding proteins from liver, spleen, and L-cell nuclear extracts. The arrow shows the specific DNA-protein complex formed. Where indicated, a 250 -fold molar excess of competitor DNA (homologous, heterologous, or nonspecific oligonucleotide [DRc, DRcM, or VW]) was included in the preincubation mixture.

gave a 2.4-fold increase in transcription compared with DRb alone and was therefore less efficient than DRc $+a+b$, which showed a 3.7-fold increase in mRNA expression (Fig. 8D and 9B). These data suggest that DRc does not activate transcription in an independent manner. In summary, the interaction of ubiquitous and tissue-specific factors with two binding sites next to the distal glucocorticoid regulatory element contributes to a positive regulation of glucocorticoid-stimulated MMTV transcription in permissive cells.

\section{DISCUSSION}

MMTV infection of mice shows a strong tropism for the mammary glands. However, other tissues such as salivary glands, lymphoid organs, seminal vesicles, prostate, and testes are also permissive for the virus. Experiments with transgenic mice carrying an MMTV LTR linked to a reporter gene showed a similar tissue specificity of MMTV expression (63, 65,72 ), demonstrating that virus entry is not the limiting factor for gene expression. Some organs, like liver and (in most studies) kidney, heart, and brain, did not express the transgene despite the widespread occurrence in these tissues of the glucocorticoid receptor, which is a strong activator of MMTV transcription, suggesting the existence of further regulatory factors. Documented mechanisms of modulating hormonal regulation include interaction of the receptor with factors that do not bind to the regulatory DNA segment but form specific and stable protein-protein complexes (82) or, more often, interaction with factors that have their binding sites on the same DNA. Strong synergistic effects on steroid hormone-induced transcription have been demonstrated by combination of nonreceptor-binding sites with a receptor-binding site $(11,73)$. Recently, it was shown that the juxtaposition of the receptor to particular factors within a specific complex influences the hor-
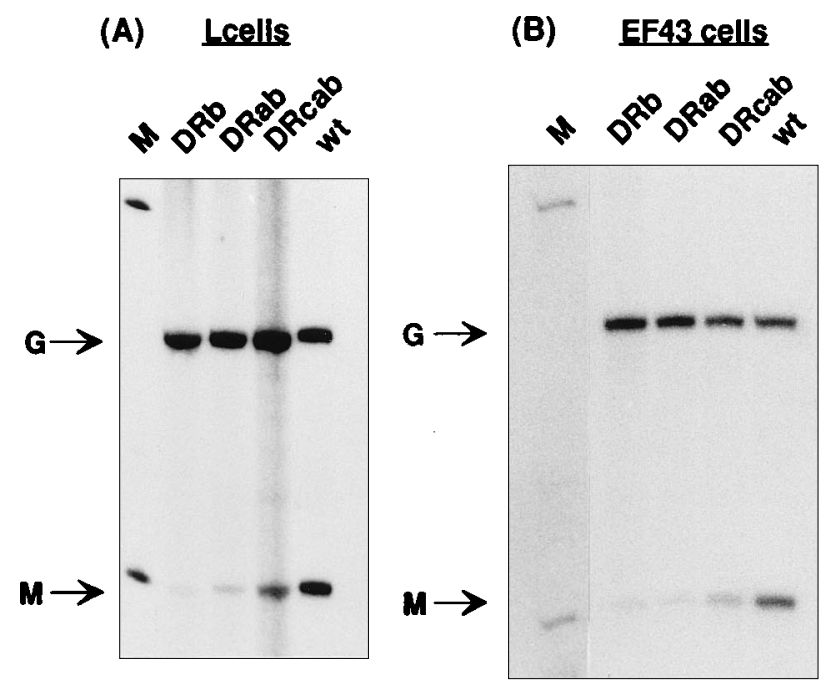

$\begin{array}{lllll}1 & 2 & 3 & 4 & 5\end{array}$
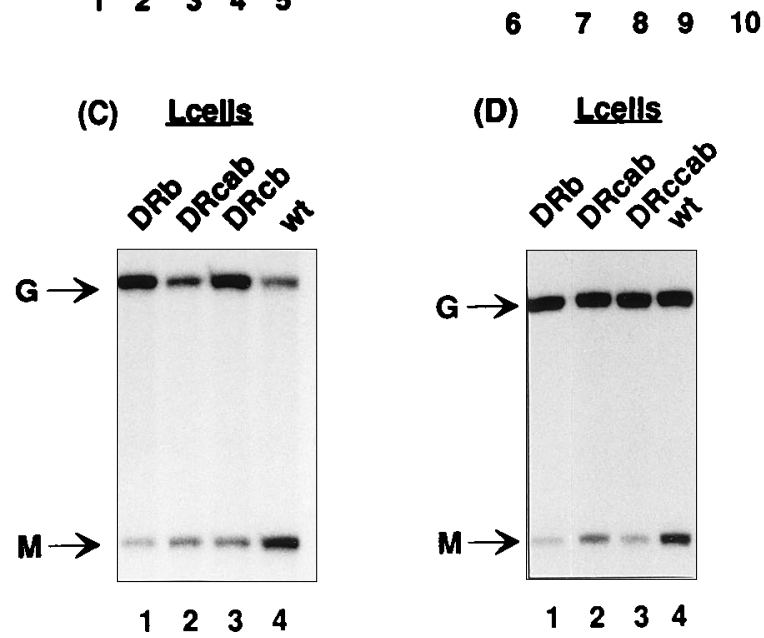

FIG. 8. S1 nuclease protection assay of RNA from transiently transfected Ltk $^{-}$cells (A, C, and D) or EF43 cells (B). Cotransfection experiments were performed with the different pLS plasmid DNAs (as indicated above each lane) and a control plasmid, pH514, carrying the rabbit $\beta$-globin gene. At least two different preparations of each pLS plasmid were used in these experiments. The cultures were treated with dexamethasone for $16 \mathrm{~h}$ before RNA extraction. The arrows indicate the 5 '-end-labeled protected fragments corresponding to the MMTV LTR probe (142 nt) (M) and the $\beta$-globin probe $(212 \mathrm{nt})(\mathrm{G})$.

mone induced transcription (2). Moreover, differential interaction of specific receptor domains with closely adjacent nonreceptor factors may determine distinct hormonal effects (60). In this report, we have shown that nonreceptor proteins binding to DNA in the vicinity of the distal glucocorticoid receptorbinding site modulate the glucocorticoid stimulation of MMTV transcription.

We analyzed three distinct binding elements in the distal region of the MMTV promoter corresponding to the glucocorticoid receptor-binding site $(\mathrm{DRb})$ and two sites for nonreceptor proteins (DRa and DRc). A possible interaction among the proteins binding to these sites is indicated in DNase I protection experiments by competition of the DRb-binding activity with the DRc sequence (Fig. 2B, lane 9; Fig. 2C, lane 3) or with the DRa sequence (Fig. 2B, lane 7) at a high molar excess of competitor. Moreover, incubation of a liver nuclear extract with a monoclonal antibody against the purified liver glucocorticoid receptor inhibited the footprint not only on the DRb site 

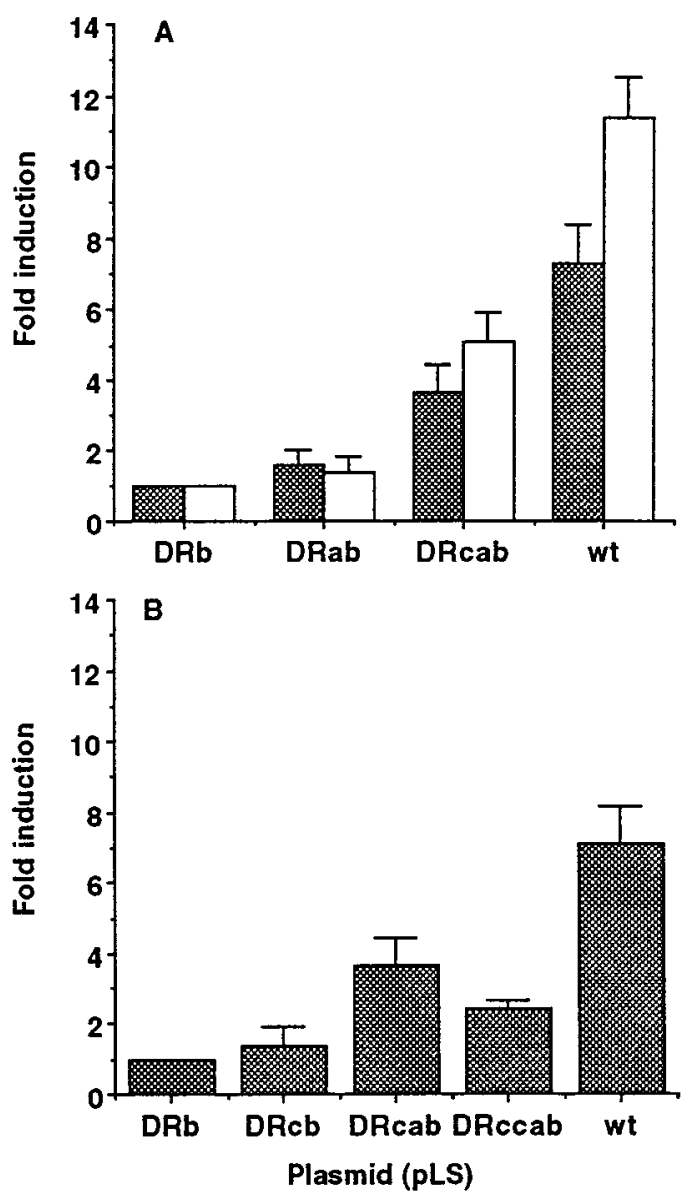

FIG. 9. Quantitation of MMTV-specific transcription in transiently transfected L cells (shaded bars) or mammary epithelial EF43 cells (open bars). The results of several S1 mapping experiments similar to the one shown in Fig. 8 were analyzed by scanning densitometry of autoradiographs, and the data were normalized to those for the $\beta$-globin internal standard. They are expressed in fold induction ( \pm standard deviation) compared with the signal found with $\mathrm{DRb}$. The number $(n)$ of transfections performed with each construct was as follows: in $\mathrm{L}$ cells, $n=5$ with the exception of DRcb and DRccab, for which $n=3$; in EF43 cells, $n=3$. wt, wild type.

but also on the DRa site (46). Although DRc was not considered in that study, a close examination of the data showed that the DRc site was also affected, confirming that the receptor interacts with both distal binding activities. An interaction between the glucocorticoid receptor and the DRa- or DRc-binding activity in solution could lead to a titration of the receptor with either competitor DNA.

Further evidence for the interaction of the three binding activities came from transient transfection experiments with various constructs, showing cooperation of DRa, DRb, and DRc in the positive modulation of MMTV promoter activity in permissive cells. Using two permissive cell lines ( $\mathrm{Ltk}^{-}$fibroblasts and EF43 mammary epithelial cells), we found that compared with the pLS DRb plasmid containing only the DRb site, the addition of DRa upstream of DRb did not significantly change the level of transcription, whereas the further addition of DRc, in DRc $+\mathrm{a}+\mathrm{b}$, increased the level of hormone-induced transcription by four- to fivefold (Fig. 8 and 9). In our assay, the basal level was undetectable. However, deletions encompassing this area of the LTR have been shown not to affect the basal level $(21,81)$. Interestingly, the presence of the DRc element directly adjacent to the glucocorticoid receptor-bind- ing site (DRb), in the absence of DRa, was no longer able to significantly influence the level of transcription. This result demonstrates that the DRc sequence cannot activate transcription on its own but must act in concert with the two other binding sites identified in the DR. In a plasmid construction with the C3H MMTV LTR, a 23-bp substitution between -223 and -200 was shown to reduce the dexamethasone-induced expression of a reporter gene, particularly in a mammary cell line, by about $30 \%$ (21). We observed that the sequence of this $\mathrm{C} 3 \mathrm{H}$ element was similar to that of DRc of the GR MMTV $(-203$ to -225$)$. Thus, the 23-bp substitution replaced the DRc-binding site described in this study. Interestingly, the sequence of the $\mathrm{C} 3 \mathrm{H}$ MMTV-K variant differs from the sequence of DRc of the GR MMTV only in its $5^{\prime}$ end (from position -218) $(5,79)$. The factor(s) binding the DRc sequence probably also recognizes the $\mathrm{C} 3 \mathrm{H}$ MMTV-K sequence since the DRc contact points determined by methylation interference assay (Fig. 4D) were located in the conserved $3^{\prime}$ end and a gel retardation assay comparing the two sequences showed similar migrations of the protein-DNA complexes (data not shown). Therefore, these results in different MMTV strains show the importance of DRc (or equivalent) in the stimulation of MMTV transcription in permissive cells. Furthermore, our data demonstrate the need for cooperation between DRc and the neighboring distal binding activities (DRb and DRa). In this context, analysis of the mouse T-cell receptor enhancer provides an interesting model (19). Three DNAbinding factors, assembled into a highly specific three-dimensional nucleoprotein complex, activated transcription of the T-cell receptor, and changes in the relative positions or orientations of the protein binding sites led to inactivation of the complex.

The control of MMTV transcription in permissive tissues seems to occur at several levels. In mammary glands, maximal MMTV expression is obtained by hormonal stimulation acting through the HRE together with transactivation by mammary cell-activating factors. These determinants of mammary cellspecific expression have been described at the extreme $5^{\prime}$ part of the U3 region (around position -1000) in several independent studies $(21,41,50,51,81)$, although no agreement has yet been reached on their precise location. This regulation seems to be achieved by a concerted action of transcription factors binding to multiple regulatory sites in this region, including MAF (mammary cell-activating factor) and a member of the CTF/NF-1 family (49), MP4 (41), a putative factor binding to a mammary gland enhancer (51), and factors described according to their DNA recognition sites $(49,81)$. Using transgenic mice carrying an MMTV LTR deleted of all 5' LTR sequences upstream of -364 , Mok et al. (51) showed an increase of transgene expression in lactating females comparable to that seen in mice carrying the complete LTR. These authors concluded that the major determinant of the strong increase of viral expression that occurs during lactation must include the glucocorticoid response elements. Our results are interesting in this context, as they point to elements that are capable of modulating the hormonal response. We have demonstrated that cooperation of the glucocorticoid receptor with two other distinct binding activities in the DR, in the absence of the $5^{\prime}$ end of the LTR, is sufficient to significantly increase the level of MMTV transcription in permissive cells. Moreover, a lower but significant level of expression occurs in other permissive tissues such as salivary glands, spleen, and lymphocytes in which regulatory factors different from the mammary cell-activating ones may play an important role. In our studies of the DR, the tissue specificity of factors binding to DRa was suggested by the presence of hypersensitive sites in the footprints 
observed only with nuclear extracts from nonpermissive tissues (liver [Fig. 2] and kidney [data not shown]). Gel retardation assays with wild-type (DRa) and mutated (DRaML) oligonucleotides (Fig. 3A, 6A, and 6B) and methylation interference assays (Fig. 5) demonstrated that the major DRa-binding activities are indeed distinct and specific to permissive (mammary gland and mammary epithelial cell lines EF43 and GR) or nonpermissive (liver and kidney) tissues and cell lines. A very low concentration of the permissive-type DRa factor was observed occasionally in nonpermissive tissue extracts; however, this did not influence the pattern of DNase I footprints observed with these extracts. We showed by gel retardation assays with a mutated DRaMS oligonucleotide that the DRa-binding activity is the same in permissive tissues of different origin (e.g., mammary and lymphoid [Fig. 6C]), in contrast to the mammary cell-activating factors mentioned above (MAF and MP4), which were expressed mainly in cells of mammary origin.

MMTV is known to be expressed in lymphoid cells (42), and infected lymphocytes were shown to harbor persistent virus $(30,78)$. Moreover, they play an essential role in the infectious process, as an MMTV-encoded product (superantigen) expressed in B cells directly influences the host immune system $(1,14)$. The molecular mechanisms controlling MMTV expression in lymphocytes are, however, not well understood. King and Corley (36) showed that the level of MMTV transcription can be increased by treatment of B cells with various substances such as lipopolysaccharide or lymphokines via a pathway that is different from the one used by dexamethasone. As our results suggest that the factors binding DRa are similar in nuclear extracts from the mammary gland and various lymphoid tissues or cell lines, and as a particularly strong binding activity for the DRc sequence was observed in spleen extracts, it is possible that these regions positively influence the hormone-regulated pathway in lymphoid tissues. Thus, we plan to test the expression in B-cell lines of our plasmids carrying different parts of the DR.

In the absence of a sufficiently differentiated transfectable liver cell line which could prevent MMTV transcription, it is not yet possible to test our hypothesis that the protein(s) binding to the DRa site may repress glucocorticoid-induced transcription in nonpermissive cells, for example by competing with a positive regulatory DRa-binding factor. Alternatively, repression may occur by direct interaction between the DRa-binding factor and the receptor or by steric hindrance of contacts between the receptor and the transcription initiation complex $(53,61)$. The strong signal observed in gel retardation assays with liver and kidney nuclear extracts suggests that the DRabinding activity is abundant in these tissues or binds with a high affinity to the DRa site (Fig. 2A and 6B). Complexes with similar mobility were not observed with extracts from several transfectable hepatoma cell lines (mouse FMH-202 [58], rat FTO-2B [35], and human HepG2 [data not shown]), suggesting that these cell lines lack the DRa-binding protein found in liver. The expression of one hepatocyte factor may be dependent on another, as shown recently in the case of a dedifferentiated hepatoma cell line in which the absence of hepatic nuclear factor 4 (HNF-4) also abolished the expression of HNF-1 $\alpha$ (38). The recent identification of these and other liver-enriched transcription factors and of the genes encoding them (which can be introduced into cultured cells) $(34,71)$ will allow us to test the expression of a negative-acting factor or may reveal novel regulatory interactions.

The sequence TTTAAATAA of DRa fits relatively well with the reported consensus binding site for the transcription factor C/EBP (MTTRCNNMA, where $\mathrm{M}$ is $\mathrm{C}$ or $\mathrm{A}, \mathrm{N}$ is $\mathrm{A}, \mathrm{C}, \mathrm{G}$, or
$\mathrm{T}$, and $\mathrm{R}$ is $\mathrm{G}$ or $\mathrm{A})$ (66). Furthermore, our sequence shows a high degree of homology ( 8 of $9 \mathrm{bp}$ ) with a low-affinity binding site for $\mathrm{C} / \mathrm{EBP}$ in the $\mathrm{C}$ region of the chicken vitellogenin II promoter, which is active in hepatocytes (70). In a gel retardation assay with a DRa probe, an oligonucleotide containing the CAAT motif of the herpes simplex virus thymidine kinase gene that also binds the factor C/EBP (23) efficiently competed for the complex formed with spleen nuclear extract but not the major liver complex (data not shown). Interestingly, recently described members of the $\mathrm{C} / \mathrm{EBP}$ family are not restricted to the liver but are expressed in many different tissues and cell lines (64). Therefore, we are pursuing the idea that the DRa factor found mainly in permissive tissues (spleen) may be a member of this family. HNF-3 binds an 11-bp motif located in the upstream sequence of the tyrosine aminotransferase (TAT) gene that shows only 6-bp homology with the HNF-3 consensus binding sequence (55). Interestingly, we observed a sequence in DRa which has six base identities with this TAT$2.5 \mathrm{HNF}-3$ binding site. A functional cooperation between a distantly located glucocorticoid regulatory element and an HNF-3-binding site results in activation of TAT gene transcription (55). On the other hand, HNF-3 has also been shown to act as an inhibitor of transcription (24). We are currently investigating if the DRa factor in nonpermissive tissues (liver) is a member of the HNF-3 family (15). A search of various data banks of transcription factor-binding sites did not reveal any other significant homologies with the DRa or DRc site.

In conclusion, we have established that in permissive cells, the combination of a tissue-specific factor(s) and a ubiquitous factor(s) positively modulates the transcriptional stimulation elicited by the glucocorticoid receptor. This positive effect can be interpreted as a facilitation or stabilization of the interaction between the receptor and its binding site and/or at the level of activation of the transcriptional machinery by interaction with targets within the basal transcription complex (75).

\section{ACKNOWLEDGMENTS}

We are grateful to Heidi Diggelmann for support and helpful discussions. We also thank P. Dowling for supplying oligonucleotides and our colleagues P. Beard, J. Mirkovitch, and R. Tyrrell for comments on the manuscript.

This work was supported by the Swiss National Science Fund.

\section{REFERENCES}

1. Acha-Orbea, H., A. N. Shakhov, L. Scarpellino, E. Kolb, V. Müller, A. Vessaz-Shaw, R. Fuchs, K. Blöchlinger, P. Rollini, J. Billotte, M. Sarafidou, H. R. MacDonald, and H. Diggelmann. 1991. Clonal deletion of V- $\beta 14-$ bearing $\mathrm{T}$ cells in mice transgenic for mammary tumor virus. Nature (London) 350:207-211

2. Adler, A. J., A. Scheller, and D. M. Robins. 1993. The stringency and magnitude of androgen-specific gene activation are combinatorial functions of receptor and nonreceptor binding site sequences. Mol. Cell. Biol. 13:63266335 .

3. Allan, G. F., N. H. Ing, S. Y. Tsai, G. Srinivasan, N. L. Weigel, E. B. Thompson, M.-J. Tsai, and B. W. O'Malley. 1991. Synergism between steroid response and promoter elements during cell-free transcription. J. Biol. Chem. 266:5905-5010.

4. Banerji, J., S. Rusconi, and W. Schaffner. 1981. Expression of a $\beta$-globin gene is enhanced by remote SV40 DNA sequences. Cell 27:299-308.

5. Brandt-Carlson, C., J. S. Butel, and D. A. Wheeler. 1993. Phylogenetic and structural analyses of MMTV LTR ORF sequences of exogenous and endogenous origins. Virology 193:171-185.

6. Brüggemeier, U., M. Kalff, S. Franke, C. Scheidereit, and M. Beato. 1991. Ubiquitous transcription factor OTF-1 mediates induction of the MMTV promoter through synergistic interaction with hormone receptors. Cell 64: $565-572$.

7. Buetti, E. 1994. Stably integrated mouse mammary tumor virus long terminal repeat DNA requires the octamer motifs for basal promoter activity. Mol. Cell. Biol. 14:1191-1203.

8. Buetti, E., and H. Diggelmann. 1981. Cloned mouse mammary tumor virus DNA is biologically active in transfected mouse cells and its expression is 
stimulated by glucocorticoid hormones. Cell 23:335-345.

9. Buetti, E., and H. Diggelmann. 1983. Glucocorticoid regulation of mouse mammary tumor virus: identification of a short essential DNA region. EMBO J. 2:1423-1429.

10. Buetti, E., and B. Kühnel. 1986. Distinct sequence elements involved in the glucocorticoid regulation of the mouse mammary tumor virus promoter identified by linker scanning mutagenesis. J. Mol. Biol. 190:379-389.

11. Buetti, E., B. Kühnel, and H. Diggelmann. 1989. Dual function of a nuclear factor 1 binding site in MMTV transcription regulation. Nucleic Acids Res. 17:3065-3078.

12. Cato, A. C. B., R. Miksicek, G. Schütz, J. Arnemann, and M. Beato. 1986. The hormone regulatory element of mouse mammary tumor virus mediates progesterone induction. EMBO J. 5:2237-2240.

13. Cato, A. C. B., P. Skroch, J. Weinmann, P. Butkeraitis, and H. Ponta. 1988. DNA sequences outside the receptor-binding sites differentially modulate the responsiveness of the mouse mammary tumour virus promoter to various steroid hormones. EMBO J. 7:1403-1410.

14. Choi, Y., J. W. Kappler, and P. Marrack. 1991. A superantigen encoded in the open reading frame of the $3^{\prime}$ long terminal repeat of mouse mammary tumour virus. Nature (London) 350:203-207.

15. Clevidence, D. E., D. G. Overdier, W. Tao, X. Quian, L. Pani, E. Lai, and R. H. Costa. 1993. Identification of nine tissue-specific transcription factors of the hepatocyte nuclear factor 3/forkhead DNA-binding-domain family. Proc. Natl. Acad. Sci. USA 90:3948-3952.

16. Darbre, P., M. Page, and R. J. B. King. 1986. Androgen regulation by the long terminal repeat of mouse mammary tumor virus. Mol. Cell. Biol. 6:2847-2854.

17. De Groot, R. P., and P. Sassone-Corsi. 1992. Activation of jun/AP-1 by protein kinase A. Oncogene 7:2281-2286.

18. Galas, D., and A. Schmitz. 1978. DNAase footprinting: a simple method for the detection of protein-DNA-binding specificity. Nucleic Acids Res. 5:3157-3170.

19. Giese, K., J. Cox, and R. Grosschedl. 1992. The HMG domain of lymphoid enhancer factor 1 bends DNA and facilitates assembly of functional nucleoprotein structures. Cell 69:185-195.

20. Gorski, K., M. Carneiro, and U. Schibler. 1986. Tissue-specific in vitro transcription from the mouse albumin promoter. Cell 47:767-776.

21. Gouilleux, F., B. Sola, B. Couette, and H. Richard-Foy. 1991. Cooperation between structural elements in hormono-regulated transcription from the mouse mammary tumor virus promoter. Nucleic Acids Res. 19:1563-1569.

22. Gowland, P. L., and E. Buetti. 1989. Mutations in the hormone regulatory element of mouse mammary tumor virus differentially affect the response to progestins, androgens, and glucocorticoids. Mol. Cell. Biol. 9:3999-4008.

23. Graves, B. J., P. F. Johnson, and S. L. McKnight. 1986. Homologous recognition of a promoter domain common to the MSV LTR and the HSV tk gene. Cell 44:565-576.

24. Gregori, C., A. Kahn, and A.-L. Pichard. 1993. Competition between transcription factors HNF-1 and HNF-3, and alternative cell-specific activation by $\mathrm{DBP}$ and $\mathrm{C} / \mathrm{EBP}$ contribute to the regulation of the liver-specific aldolase B promoter. Nucleic Acids Res. 21:897-903.

25. Gustafsson, J. A., J. Carlstedt-Duke, L. Poellinger, S. Okret, A. C. Wikström, M. Brönnegard, M. Gillner, Y. Dong, K. Fuxe, A. Cintra, A. Härfstrand, and L. Agnati. 1987. Biochemistry, molecular biology, and physiology of the glucocorticoid receptor. Endocrine Rev. 8:185-234.

26. Günzburg, W. H., and B. Salmons. 1992. Factors controlling the expression of mouse mammary tumour virus. Biochem. J. 283:625-632.

27. Hagenbüchle, O., and P. K. Wellauer. 1992. A rapid method for the isolation of DNA-binding proteins from purified nuclei of tissues and cells in culture. Nucleic Acids Res. 20:3555-3559.

28. Ham, J., A. Thomson, M. Needham, P. Webb, and M. Parker. 1988. Characterization of response elements for androgens, glucocorticoids and progestins in mouse mammary tumour virus. Nucleic Acids Res. 16:5263-5276.

29. Härtig, E., B. Nierlich, S. Mink, G. Nebl, and A. C. B. Cato. 1993. Regulation of expression of mouse mammary tumor virus through sequences located in the hormone response element: involvement of cell-cell contact and a negative regulatory factor. J. Virol. 67:813-821.

30. Held, W., G. A. Waanders, A. N. Shakhov, L. Scarpellino, H. Acha-Orbea, and H. R. MacDonald. 1993. Superantigen-induced immune stimulation amplifies mouse mammary tumor virus infection and allows virus transmission. Cell 74:529-540.

31. Hsu, C.-L. L., C. Fabritius, and J. Dudley. 1988. Mouse mammary tumor virus proviruses in T-cell lymphomas lack a negative regulatory element in the long terminal repeat. J. Virol. 62:4644-4652.

32. Huang, A. L., M. C. Ostrowski, D. Berard, and G. L. Hager. 1981. Glucocorticoid regulation of the Ha-MuSV p21 gene conferred by sequences from mouse mammary tumor virus. Cell 27:245-255.

33. Hynes, N., A. J. J. van Ooyen, N. Kennedy, P. Herrlich, H. Ponta, and B. Groner. 1983. Subfragments of the large terminal repeat cause glucocorticoid-responsive expression of mouse mammary tumor virus and of an adjacent gene. Proc. Natl. Acad. Sci. USA 80:3637-3641.

34. Jackson, D. A., K. E. Rowader, K. Stevens, C. Jiang, P. Milos, and K. S. Zaret. 1993. Modulation of liver-specific transcription by interactions be- tween hepatocyte nuclear factor 3 and nuclear factor 1 binding DNA in close apposition. Mol. Cell. Biol. 13:2401-2410.

35. Killary, A. M., T. G. Lugo, and R. E. K. Fournier. 1984. Isolation of thymidine kinase deficient rat hepatoma cells by selection with bromo-deoxyuridine, Hoechst 33258, and visible light. Biochem. Genet. 22:201-213.

36. King, L. B., and R. B. Corley. 1990. Lipopolysaccharide and dexamethasone induce mouse mammary tumor proviral gene expression and differentiation in B lymphocytes through distinct regulatory pathways. Mol. Cell. Biol. 10:4211-4220.

37. Kühnel, B., E. Buetti, and H. Diggelmann. 1986. Functional analysis of the glucocorticoid regulatory elements present in the mouse mammary tumor virus long terminal repeat. A synthetic distal binding site can replace the proximal binding domain. J. Mol. Biol. 190:367-378.

38. Kuo, C. J., P. B. Conley, L. Chen, F. M. Sladeck, J. E. Darnell, Jr., and G. R. Crabtree. 1992. A transcriptional hierarchy involved in mammalian cell-type specification. Nature (London) 355:458-460.

39. Lee, F., R. Mulligan, P. Berg, and G. Ringold. 1981. Glucocorticoids regulate expression of dihydrofolate reductase cDNA in mouse mammary tumour. Nature (London) 294:228-232.

40. Lee, W. T., O. Prakash, D. Klein, and N. H. Sarkar. 1987. Structural alterations in the long terminal repeat of an acquired mouse mammary tumor virus provirus in a T-cell leukemia of DBA/2 mice. Virology 159:39-48.

41. Lefebvre, P., D. S. Berard, M. G. Cordingley, and G. L. Hager. 1991. Two regions of the mouse mammary tumor virus long terminal repeat regulate the activity of its promoter in mammary cell lines. Mol. Cell. Biol. 11:2529 2537.

42. Lund, F. E., and R. B. Corley. 1991. Regulated expression of mouse mammary tumor proviral genes in cells of the B lineage. J. Exp. Med. 174:14391450 .

43. Majors, J. E., and H. E. Varmus. 1983. A small region of the mouse mammary tumor virus long terminal repeat confers glucocorticoid hormone regulation on a linked heterologous gene. Proc. Natl. Acad. Sci. USA 80:58665870 .

44. Matsui, Y., S. A. Halter, J. T. Holt, B. L. M. Hogan, and R. J. Coffey. 1990 Development of mammary hyperplasia and neoplasia in MMTV-TGF $\alpha$ transgenic mice. Cell 61:1147-1155.

45. Maxam, A. M., and W. Gilbert. 1977. A new method for sequencing. Proc. Natl. Acad. Sci. USA 74:560-564.

46. Meulia, T., and H. Diggelmann. 1990. Tissue specific factors and glucocorticoid receptors present in nuclear extracts bind next to each other in the promoter region of mouse mammary tumor virus. J. Mol. Biol. 216:859-872.

47. Michalides, R. E., E. Wagenaar, and P. Weijers. 1985. Rearrangements in the long terminal repeat of extra mouse mammary tumor provirus in T-cel leukemias of mouse strain GR result in a novel enhancer-like structure. Mol. Cell. Biol. 5:823-830.

48. Miksicek, R., U. Borgmeyer, and J. Nowock. 1987. Interaction of the TGGCA-binding protein with upstream sequences is required for efficient transcription of mouse mammary tumor virus. EMBO J. 6:1355-1360.

49. Mink, S., E. Härtig, P. Jennewein, W. Doppler, and A. C. B. Cato. 1992. A mammary cell-specific enhancer in mouse mammary tumor virus DNA is composed of multiple regulatory elements including binding sites for CTF/ $\mathrm{NF} 1$ and a novel transcription factor, mammary cell-activating factor. Mol. Cell. Biol. 12:4906-4918.

50. Mink, S., H. Ponta, and A. C. B. Cato. 1990. The long terminal repeat region of the mouse mammary tumour virus contains multiple regulatory elements. Nucleic Acids Res. 18:2017-2024.

51. Mok, E., T. V. Golovkina, and S. R. Ross. 1992. A mouse mammary tumor virus mammary gland enhancer confers tissue-specific but not lactationdependent expression in transgenic mice. J. Virol. 66:7529-7532.

52. Morley, K., M. G. Toohey, and D. O. Peterson. 1987. Transcriptional repression of a hormone-responsive promoter. Nucleic Acids Res. 15:6973-6989.

53. Muller, M., and R. Renkawitz. 1991. The glucocorticoid receptor. Biochim. Biophys. Acta 1088:171-182.

54. Muller, W. J., F. S. Lee, C. Dickson, G. Peters, P. Pattengale, and P. Leder 1990. The int-2 gene product acts as an epithelial growth factor in transgenic mice. EMBO J. 9:907-913.

55. Nitsch, D., M. Boshart, and G. Schütz. 1993. Activation of the tyrosine aminotransferase gene is dependent on synergy between liver-specific and hormone-responsive elements. Proc. Natl. Acad. Sci. USA 90:5479-5483.

56. Nowock, J., U. Borgmeyer, A. W. Püschel, R. A. W. Rupp, and A. E. Sippel. 1985. The TGGCA protein binds to the MMTV-LTR, the adenovirus origin of replication and the BK virus enhancer. Nucleic Acids Res. 13:2045-2061.

57. Paterson, T, and R. D. Everett. 1988. The regions of the herpes simplex virus type 1 immediate early protein Vmw 175 required for site specific DNA binding closely correspond to those involved in transcriptional regulation. Nucleic Acids Res. 16:11005-11025.

58. Paul, D., M. Höhne, C. Pinkert, A. Piasecki, E. Ummelmann, and R. L. Brinster. 1988. Immortalized differentiated hepatocyte lines derived from transgenic mice harboring SV40 T-antigen genes. Exp. Cell Res. 175:354362.

59. Payvar, F., D. DeFranco, G. L. Firestone, B. Edgar, O. Wrange, S. Okret, J. A. Gustafsson, and K. R. Yamamoto. 1983. Sequence-specific binding of 
glucocorticoid receptor to MTV DNA at sites within and upstream of the transcribed region. Cell 35:381-392.

60. Pearce, D., and K. R. Yamamoto. 1993. Mineralocorticoid and glucocorticoid receptor activities distinguished by nonreceptor factors at a composite response element. Science 259:1161-1165.

61. Renkawitz, R. 1990. Transcriptional repression in eukaryotes. Trends Genet. 6:192-197.

62. Ringold, G. M., R. D. Cardiff, H. E. Varmus, and K. R. Yamamoto. 1977. Infection of cultured rat hepatoma cells by mouse mammary tumor virus. Cell 10:11-18.

63. Rollini, P., J. Billotte, E. Kolb, and H. Diggelmann. 1992. Expression pattern of mouse mammary tumor virus in transgenic mice carrying exogenous proviruses of different origin. J. Virol. 66:4580-4586.

64. Roman, C., J. S. Platero, J. Shuman, and K. Calame. 1990. Ig/EBP-1: a ubiquitously expressed immunoglobulin enhancer binding protein that is similar to C/EBP and heterodimerizes with C/EBP. Genes Dev. 4:1404-1415.

65. Ross, S. R., C.-L. L. Hsu, Y. Choi, E. Mok, and J. P. Dudley. 1990. Negative regulation in correct tissue-specific expression of mouse mammary tumor virus in transgenic mice. Mol. Cell. Biol. 10:5822-5829.

66. Ryden, T. A., and K. Beemon. 1989. Avian retroviral long terminal repeats bind CCAAT/enhancer-binding protein. Mol. Cell. Biol. 9:1155-1164.

67. Sawadogo, M., and R. G. Roeder. 1985. Interaction of a gene-specific transcription factor with the adenovirus major late promoter upstream of the TATA box region. Cell 43:165-175.

68. Schatt, M. D., S. Rusconi, and W. Schaffner. 1990. A single DNA-binding transcription factor is sufficient for activation from a distant enhancer and/or from a promoter position. EMBO J. 9:481-487.

69. Scheidereit, C., S. Geisse, H. M. Westphal, and M. Beato. 1983. The glucocorticoid receptor binds to defined nucleotide sequences near the promoter of mouse mammary tumour virus. Nature (London) 304:749-752.

70. Seal, S. N., D. L. Davis, and J. B. E. Burch. 1991. Mutational studies reveal a complex set of positive and negative control elements within the chicken vitellogenin II promoter. Mol. Cell. Biol. 11:2704-2717.

71. Sladek, F. M., and J. E. Darnell, Jr. 1992. Mechanisms of liver-specific gene expression. Curr. Opin. Genet. Dev. 2:256-259.

72. Stewart, T. A., P. G. Hollingshead, and S. L. Pitts. 1988. Multiple regulatory domains in the mouse mammary tumor virus long terminal repeat revealed by analysis of fusion genes in transgenic mice. Mol. Cell. Biol. 8:473-479.
73. Strähle, U., W. Schmid, and G. Schütz. 1988. Synergistic action of the glucocorticoid receptor with transcription factors. EMBO J. 7:3389-3395.

74. Theunissen, H. J. M. M. Paardekooper, L. J. Maduro, R. J. A. M. Michalides, and R. Nusse. 1989. Phorbol ester-inducible T-cell-specific expression of variant mouse mammary tumor virus long terminal repeats. J. Virol 63:3466-3471.

75. Tjian, R., and T. Maniatis. 1994. Transcriptional activation: a complex puzzle with few easy pieces. Cell 77:5-8.

76. Toohey, M. G., J. W. Lee, M. Huang, and D. O. Peterson. 1990. Functional elements of the steroid hormone-responsive promoter of mouse mammary tumor virus. J. Virol. 64:4477-4488.

77. Tremblay, P. J., F. Pothier, T. Hoang, G. Tremblay, S. Brownstein, A Liszauer, and P. Jolicoeur. 1989. Transgenic mice carrying the mouse mammary tumor virus ras fusion gene: distinct effects in various tissues. Mol. Cell. Biol. 9:854-859.

78. Tsubura, A., I. Muneo, S. Imai, A. Murakami, N. Oyaizu, R. Yasumizu, Y. Ohnishi, H. Tanaka, S. Morii, and S. Ikehara. 1988. Intervention of T-cells in transportation of mouse mammary tumor virus (milk factor) to mammary gland cells in vivo. Cancer Res. 48:6555-6559.

79. Wellinger, J. R., M. Garcia, A. Vessaz, and H. Diggelmann. 1986. Exogenous mouse mammary tumor virus proviral DNA isolated from a kidney adenocarcinoma cell line contains alterations in the U3 region of the long terminal repeat. J. Virol. 60:1-11.

80. Yanagawa, S.-I., A. Murakami, and H. Tanaka. 1990. Extra mouse mammary tumor proviruses in DBA/2 mouse lymphomas acquire a selective advantage in lymphocytes by alteration in the U3 region of the long terminal repeat. $\mathrm{J}$. Virol. 64:2474-2483.

81. Yanagawa, S.-I., H. Tanaka, and A. Ishimoto. 1991. Identification of a nove mammary cell line-specific enhancer element in the long terminal repeat of mouse mammary tumor virus, which interacts with its hormone-responsive element. J. Virol. 65:526-531.

82. Yang-Yen, H.-F., J.-C. Chambard, Y.-L. Sun, T. Smeal, T. J. Schmidt, J. Drouin, and M. Karin. 1990. Transcriptional interference between c-Jun and the glucocorticoid receptor: mutual inhibition of DNA binding due to direct protein-protein interaction. Cell 62:1205-1215.

83. Young, H. A., T. Y. Shih, E. M. Scolnick, and W. P. Parks. 1977. Steroid induction of mouse mammary tumor virus: effect upon synthesis and degradation of viral RNA. J. Virol. 21:139-146. 